\title{
NILAI USAHA INDUSTRI PRIMER HASIL HUTAN KAYU PADA CV SINAR JAYA DI KECAMATAN CIGUDEG KABUPATEN BOGOR
}

\author{
(Business Value of the Primary Industry of Timber Forest Products at CV. Sinar Jaya
} in Cigudeg District, Bogor Regency)

\author{
Gayuh Angga Pradipta ${ }^{1}$, Tun Susdiyanti ${ }^{2}$ dan Bambang Supriono ${ }^{3}$ \\ ${ }^{1}$ Sekretariat Badan Penyuluhan dan Pengembangan Sumberdaya Manusia, KLHK \\ Gedung Manggala Wanabakti, Jl Gatot Subroto Blok 7 Jakarta Pusat 10270 \\ e-mail: apradipta@gmail.com \\ ${ }^{2}$ Fakultas Kehutanan, Universitas Nusa Bangsa \\ Jl. KH. Sholeh Iskandar KM. 4 Tanah Sereal - Bogor 16166 \\ e-mail: susdiyanti@gmail.com \\ ${ }^{3}$ Fakultas Kehutanan, Universitas Nusa Bangsa \\ Jl. KH. Sholeh Iskandar KM. 4 Tanah Sereal - Bogor 16166 \\ e-mail: $\underline{\text { b_supriono53@gmail.com }}$ \\ Correspondent author : apradipta@gmail.com
}

\begin{abstract}
ABSTRAK
Community forests are the source of raw materials for the Primary Wood Forest Products Industry at CV Sinar Jaya in Cigudeg District, Bogor Regency. Optimizing the use of these raw materials can affect the business value of the wood processing industry. The purpose of this study was to determine the yield value and to analyze the business value of sawmill activities at CV. Sinar Jaya. The research method was carried out by means of quantitative analysis methods of collecting production data by direct measurement and interviews as well as calculating the value of economic income obtained from sawmill activities and overall waste utilization, the size of wood raw materials includes 10 centimeters to 30 centimeters with a length of 2,8 meters to 3 meters. The results showed that the average yield value is 55\%, productivity is $1.51 \mathrm{~m} 3 /$ hour round wood, sawn wood is $0.83 \mathrm{~m} 3 /$ hour production cost is $R p$ 1,181,600,000.0/year, Income value is $R p$. 1,509,600,0000.00/year, net profit value is Rp. 328,000.00/year, the value of marketing costs is Rp. 0 the value of the benefit cost ratio is 1.28/year and the work performance value of logs is Rp. 12,712.89 sawn wood Rp. 22,867.14. To increase the yield, the skills of the sawing workforce must be improved to minimize damage toeach sortimen. In order for business value to increase, productivity must be intensified and the availability of raw materials must be sustainable.
\end{abstract}

Keywords: Community Forest, Forest Product Primary Industry, Redemen, Bisnis Value

\section{ABSTRAK}

Hutan rakyat menjadi sumber bahan baku Industri Primer Hasil Hutan Kayu di CV Sinar Jaya di Kecamatan Cigudeg Kabupaten Bogor. Optimalisasi penggunaan bahan baku tersebut dapat berpengaruh pada nilai usaha industri pengolahan kayu. Penelitian bertujuan untuk mengetahui nilai redemen dan menganalisis nilai usaha dari aktivitas penggergajian kayu di CV.Sinar Jaya. Metode penelitian dilakukan dengan cara metode analisis kuantitatif pengumpulan data produksi dengan cara pengukuran langsung dan wawancara serta perhitungan analisis nilai pendapatan ekonomi yang diperoleh dari aktivitas pengegergajian kayu dan pemanfaatan limbah secara keseluruhan, ukuran bahan baku kayu antara lain 10 centimer sampai dengan 30 centimer dengan panjang 2,8 meter sampai dengan 3 meter nilai redemen rata-rata sebesar $55 \%$, produktivitas $1,51 \mathrm{~m}^{3} / \mathrm{jam}$ kayu bulat, kayu gergajian $0,83 \mathrm{~m}^{3} / \mathrm{jam}$ biaya produksi Rp 1,181,600,000/tahun Nilai pendapatan Rp. 1,509,600,000/tahun, nilai keuntungan bersih Rp. 328.000/tahun, dan nilai biaya pemasaran Rp.0, nilai benefit cost ratio 1,28/tahun dan nilai prestasi kerja kayu bulat Rp.12,712.89 kayu gergajian Rp. 22,867.14. Untuk meningkatkan nilai rendemen keterampilan tenaga kerja penggergaji harus ditingkatkan untuk meminimalisir kerusakan pada masing masing sortimen. Agar nilai usaha dapat meningkat maka produktivitas harus diintensifkan dan ketersediaan bahan baku yang berkelanjutan.

Kata Kunci : Hutan Rakyat, Industri Primer Hasil Hutan, Rendemen, Nilai Ekonomi 


\section{PENDAHULUAN}

Pengelolaan dan pemanfaatan hutan harus dilakukan dengan asas kelestarian dan keberlanjutan. Hasil hutan kayu menjadi tumpuan utama penyedia bahan baku Industri Primer Hasil Hutan Kayu (IPHHK) maupun industri lanjutan. IPHHK masih memiliki daya tarik utama para pelaku dunia usaha, hal tersebut dikarenakan tingkat kebutuhan dan permintaan yang cukup tinggi. Pada sektor kehutanan, industri primer hasil hutan pengolahan kayu memiliki nilai ekonomi dari pemanfaatan langsung hasil hutan berupa kayu terutama kayu rakyat. Hardjanto (2017) menjelaskan bahwa sumber utama pemasok bahan baku IPHHK antara lain berasal dari Hutan Alam, Hutan Tanaman Industri dan Hutan Rakyat. Saat ini Hutan Rakyat menjadi sumber utama dalam pemenuhan kebutuhan bahan baku kayu industri kayu rakyat yang diusahakan oleh rakyat baik secara perorangan ataupun badan usaha masyarakat. Hutan rakyat memiliki tujuan meningkatkan kesejahteraan rakyat, memenuhi kebutuhan rakyat atas hasil hutan dan juga untuk kelestarian lingkungan

Potensi tegakan hutan rakyat di Kecamatan Cigudeg Kabupaten Bogor menjadi salah satu pemasok kebutuhan industri kayu rakyat di Cigudeg dan sekitarnya. Menurut Bakti et. al. (2018), potensi tegakan hutan rakyat di empat desa di Kecamatan Cigudeg yaitu Desa Argapura, Desa Bangun Jaya, Desa Renggas Jajar, dan Desa Banyuwangi memiliki potensi total tegakan hutan sebesar 1.213,6 $\mathrm{m}^{3}$ dengan jenis tanaman seperti Sengon, Jabon, Akasia dan Jati. Lebih lanjut, Laksono (2016) menyatakan bahwa saat ini terdapat hampir 15 industri gergajian yang ada di Kecamatan Cigudeg yang masih aktif, dengan produk utama kayu papan dengan berbagai ukuran. Permintaan pasar yang cukup tinggi dan tersedianya bahan baku pemasok dari hutan rakyat yang menjadi kebutuhan dasar berlangsungya IPHHK gergajian menjadikan usaha ini tetap berjalan dengan baik sampai dengan saat ini.
CV. Sinar Jaya merupakan salah satu IPHHK skala kecil yang ada di Kecamatan Cigudeg Kabupaten Bogor. Industri tersebut mengunakan bahan baku kayu rakyat sebagai bahan baku utama dalam kegiatan pengolahan kayu. Nilai usaha yang ada di CV. Sinar Jaya dapat mewakili nilai ekonomi dan keuntungan dalam bidang usaha dari kegiatan suatu industri. Kegiatan usaha industri tersebut sebagai acuan pelaku usaha IPHHK dalam memperkirakan nilai aset perusahaan terkini sekaligus untuk memproyeksikan arah pengembangan perusahaan di masa mendatang, Dengan mengetahui valuasi atau nilai usaha maka para pelaku usaha menerapkan berbagai strategi untuk pengembangan usaha agar dapat terus berjalan dengan baik.

Perhitungan nilai usaha industri meliputi nilai rendemen, nilai produktivitas, nilai perhitungan limbah, nilai biaya penyusutan alat, nilai biaya produksi, nilai pendapatan, nilai keuntungan bersih, nilai biaya pemasaran, nilai benefit cost ratio dan perhitungan nilai prestasi kerja. Nilai usaha berhubungan dengan penghematan dalam pemanfaatan bahan baku industri kayu rakyat. Pemanfaatan bahan baku merupakan bagian terpenting dalam pengelolaan usaha yang mengacu pada hubungan keluaran dan masukan atau output dan input, serta kemampuan dalam mengorganisasi menggunakan manajemen sumber daya secara tepat.

\section{METODE PENELITIAN}

\section{A. Pengumpulan Data}

Pengambilan data dilakukan di CV. Sinar Jaya, Kecamatan Cigudeg, Kabupaten Bogor pada kurun waktu 1 Februari - 30 April 2021 me,alui metode observasi dan wawancara. Observasi dilakukan dengan pengamatan langsung dan pencatatan data produksi di CV. Sinar Jaya. Adapun wawancara dilakukan terhadap responden yang dipilih dengan metode purposive sampling. Selain itu, dalam 
rangka memperkaya data dan informasi, dilakukan studi literatur dari berbagai sumber yang relevan.

\section{B. Pengolahan Data}

1. Volume Kayu Bulat

Pengukuran diameter dilakukan terhadap kedua bontos, diameter terpendek melalui pusat bontos diukur terlebih dahulu kemudian terpanjang melalui pusat bontos (Sopianoor et.al., 2011). Menurut Mardiatmoko et.al. (2014) dan Lampiran Peraturan Direktur Jenderal Bina Produksi Kehutanan Nomor P.14/VI-BIKPHH/2009), diameter kayu bulat dapat dihitung dengan rumus:

$$
D=\frac{1 / 2(\mathrm{~d} 1+\mathrm{d} 2)+1 / 2(\mathrm{~d} 3+\mathrm{d} 4)}{2}=\frac{\mathrm{DU}+\mathrm{DP}}{2}
$$

Di mana :

$\mathrm{d} 1=$ nilai jarak terpendek melalui pusat bontos pada bontos pangkal

$\mathrm{d} 2=$ nilai jarak terpanjang melalui pusat bontos pada bontos pangkal

d3 = nilai jarak terpanjang melalui pusat bontos pada bontos ujung

$\mathrm{d} 4=$ nilai jarak terpanjang melalui pusat bontos pada bontos ujung

DU $=$ Diameter ujung

$\mathrm{DP}=$ Diameter pangkal

Volume kayu bulat dihitung menggunakan rumus Brereton meteric yang didasarkan pada pengukuran panjang kayu (p), dan diameter kayu bulat (d) dinyatakan dalam satuan meter kubik $\left(\mathrm{m}^{3}\right)$ dinyatakan dengan rumus:

$$
V=\frac{\frac{1}{4} \pi \cdot D^{2} . P}{10.000}\left(m^{3}\right) \quad \text { atau } \quad V=\frac{0,7854 . D^{2} . P}{10.000}\left(m^{3}\right)
$$

Di mana :

$\mathrm{V}=$ Volume Kayu/isi kayu bulat

$\mathrm{D}=$ Diameter Kayu Bulat $(\mathrm{cm})$

$\mathrm{P} \quad=$ Panjang Kayu (m)

\section{Volume Kayu Gergajian}

Rumus volume kayu gergajian rumus Brereton meteric yang didasarkan pada pengukuran panjang kayu (p), lebar kayu (1) dan tebal kayu $(\mathrm{t})$.

$$
\mathbf{V}=\frac{\mathbf{P} \times \mathbf{L} \times \mathbf{T}}{10.000}\left(\mathrm{~m}^{3}\right)
$$

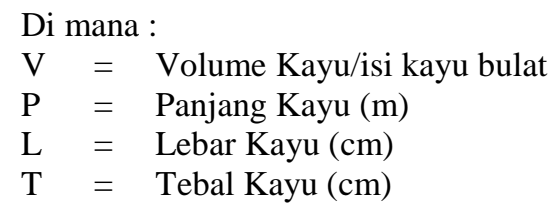

\section{Rendemen}

Rendemen adalah perbandingan hasil kayu gergajian dengan bahan baku kayu bulat. Rumus yang digunakan dalam mengukur rendemen sebagai berikut (Radam, 2011):

$$
R=\frac{\text { Output }}{\text { Input }} \times 100 \%
$$

$$
\begin{aligned}
\text { Di mana: } & \\
\mathrm{R} & =\begin{array}{l}
\text { Rendemen } \\
\text { Kayu }(\%)
\end{array} \\
\text { Output } & =\begin{array}{l}
\text { Volume Sortimen } \\
\text { Gergajian }\left(\mathrm{m}^{3}\right)
\end{array} \\
\text { Input } & =\begin{array}{l}
\text { Volume Kayu Bulat }\left(\mathrm{m}^{3}\right) \\
\text { Volume }
\end{array}
\end{aligned}
$$

\section{Produktivitas}

Produktivitas merupakan hasil dari kegiatan penggergajian yang merubah bentuk dari kayu bulat menjadi kayu gergajian berupa papan dengan berbagai ukuran. Kayu bulat merupakan variabel input sedangkan kayu gergajian merupakan output, sehingga produktivitas dalam kegiatan penggergajian kayu dapat dihitung :

$$
\text { Produktivitas }(\mathrm{m} 3 / \text { jam })=\frac{\text { Input }(\mathrm{m} 3)}{\text { Waktu }(\text { jam })}
$$

\section{Perhitungan Limbah}

Perhitungan limbah sisa hasil produksi dilakukan dengan menggunakan variabel jumlah kayu bulat $\mathrm{m}^{3}$ (input) dan jumlah (output) yang dihasilkan. Uar (2016) menyatakan bahwa limbah kayu gergajian diperoleh dengan persamaan :

$$
\text { Limbah }=\text { Input }\left(\mathbf{m}^{3}\right)-\text { Output }\left(\mathbf{m}^{3}\right)
$$




\section{Biaya Penyusutan}

Biaya penyusutan secara periodik dapat dihitung menggunakan metode garis lurus (Sari, 2018).

$$
\begin{aligned}
& \text { Penyusutan per tahun }=\frac{\boldsymbol{M}-\boldsymbol{R}}{\boldsymbol{N}} \\
& \begin{array}{l}
\text { Di mana : } \\
\mathrm{M}=\text { Harga beli asset (Rupiah) } \\
\mathrm{R}=\text { Nilai sisa atau harga rongsokan } \\
\mathrm{N}=10 \% \text { dari harga baru (Rupiah) } \\
\mathrm{Nasa} \text { Pakai (Tahun) }
\end{array}
\end{aligned}
$$

\section{Biaya Produksi}

Asyisifa (2009) menyatakan bahwa biaya produksi (total cost) dikelompokan menjadi biaya tetap (fixed cost) dan biaya tidak tetap (variable cost). Biaya tetap terdiri dari biaya gaji pegawai, biaya administrasi, biaya pemeliharaan dan biaya reparasi peralatan dan, biaya penyusutan, listrik, bahan bakar minyak, dan biaya lain-lain. Sedangkan biaya tidak tetap terdiri dari bahan baku kayu dan upah tenaga kerja.

$$
\mathbf{T C}=\mathbf{F C}+\mathrm{VC}
$$

$$
\begin{aligned}
& \text { Di mana : } \\
& \text { TC }=\text { Total Cost (Rupiah) } \\
& \text { FC }=\text { Fixed Cost (Rupiah) } \\
& \text { VC }=\text { Variable Cost (Rupiah) }
\end{aligned}
$$

\section{Nilai Pendapatan}

Nilai pendapatan dapat dihitung menggunakan rumus :

$$
\mathbf{T R}=\mathbf{P} \times \mathbf{Q}
$$

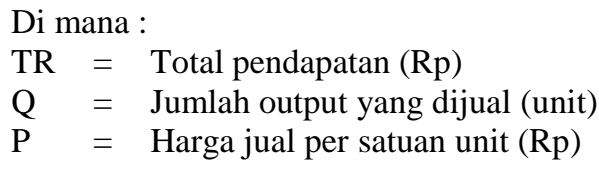

\section{Nilai Keuntungan Bersih}

Keuntungan bersih (Nett Profit) didapatkan berdasar rumus :

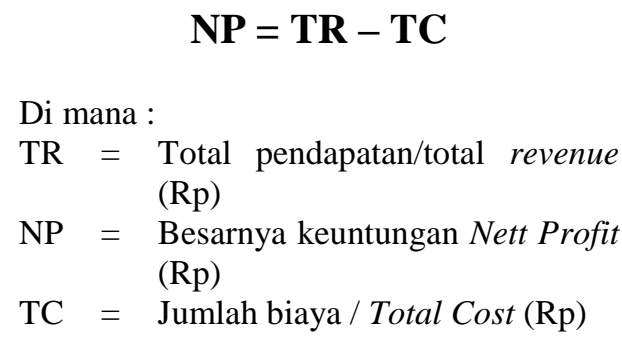$$
\mathbf{N P}=\mathbf{T R}-\mathbf{T C}
$$

Di mana :

$\mathrm{TR}=$ Total pendapatan/total revenue (Rp)

$\mathrm{NP}=$ Besarnya keuntungan Nett Profit (Rp)

$\mathrm{TC}=$ Jumlah biaya / Total Cost $(\mathrm{Rp})$

\section{Nilai Biaya Pemasaran}

Besar keseluruhan biaya yang dikeluarkan dalam kegiatan pemasaran dihitung dengan menjumlahkan komponen komponen biaya pemasaran yang meliputi biaya pengangkutan dan biaya bongkar muat.

\section{Nilai Benefit Cost Ratio}

Benefit Cost Ratio (BCR) adalah perbandingan antara penerimaan total dan biaya total. BCR dapat dihitung dengan rumus (Mazni et. al., 2017) adalah:

$$
\mathrm{BCR}=\frac{B}{C}
$$

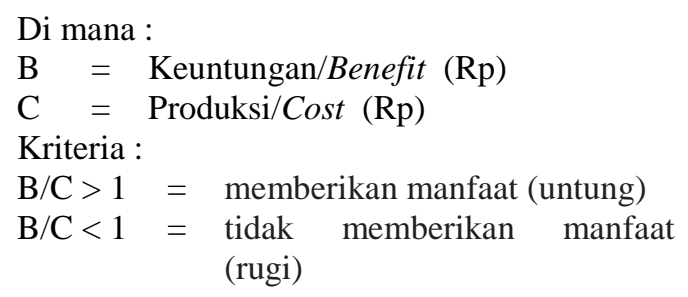

\section{Pendapatan Upah (Prestasi Kerja)}

Metode perhitungan prestasi kerja upah dilakukan berdasarkan perbandingan upah tarif per hari atau metode perhitungan pendapatan atau prestasi kerja (Taher, 2017) :

$$
\mathbf{P}=\frac{\text { Upah }}{\text { V sor }}
$$

$$
\begin{aligned}
& \text { Di mana : } \\
& \mathrm{P} \quad=\text { Pendapatan }\left(\mathrm{Rp} / \mathrm{m}^{3}\right) \\
& \mathrm{V} \text { sor }=\text { Volume Sortimen }\left(\mathrm{m}^{3} \text { per hari }\right) \\
& \text { Upah = Upah borongan }(\mathrm{Rp}) \text { per hari atau } \\
& \text { tarif per jam }
\end{aligned}
$$

\section{Analisis Data}

Analisis data penelitian ini dilakukan dengan menggunakan analisis deskritif, yaitu menggambarkan dan menganalisis suatu hasil 
penelitian tetapi tidak digunakan untuk membuat kesimpulan yang lebih luas (Sugiyono, 2005).

\section{HASIL DAN PEMBAHASAN}

\section{A. Rendemen}

Rendemen diukur untuk pengolahan kayu dengan diameter antara 10-30 $\mathrm{cm}$ dan panjang

Tabel 1. Nilai Rendemen

\begin{tabular}{cccccc}
\multicolumn{7}{l}{ Tabel 1. Nilai Rendemen } \\
\hline No & $\begin{array}{c}\text { Jumlah Kayu } \\
\text { Bulat / Batang }\end{array}$ & $\begin{array}{c}\text { Volume Kayu } \\
\text { Bulat }\left(\mathrm{m}^{3}\right)\end{array}$ & $\begin{array}{c}\text { Jumlah Kayu } \\
\text { Gergajian Keping }\end{array}$ & $\begin{array}{c}\text { Volume Kayu } \\
\text { Gergajian }\left(\mathrm{m}^{3}\right)\end{array}$ & $\begin{array}{c}\text { Rata Rata } \\
\text { Rendemen (\%) }\end{array}$ \\
\hline 1 & 120 & 11.45 & 670 & 6.61 & 57.68 \\
2 & 180 & 14.62 & 642 & 7.72 & 53.63 \\
3 & 183 & 10.15 & 564 & 5.66 & 53.50 \\
Rata & 161 & 12.07 & 625.33 & 6.66 & 54.94 \\
Rata & 162 & & & \\
\hline
\end{tabular}

Tabel 1 menunjukan rendemen pengolahan kayu rata-rata bernilai 54,94\% Hasil ini masih sesuai range yang diperbolehkan menurut Peraturan Direktur Jenderal Bina Usaha Kehutanan No. P.12/VIBPPHH/2014 tentang Rendemen Kayu Olahan Industri Primer Hasil Hutan Kayu, yakni 45$65 \%$. Dalam penelitian ini sebagian besar kayu tidak terdapat cacat yang mereduksi. Nilai rendemen sangat penting bagi pengusaha untuk menjadi bahan pertimbangan perhitungan meminimalkan biaya produksi sehingga harga jual dapat bersaing dengan perusahaan lain.

\section{Produktivitas}

Nilai produktivitas dihitung untuk mendapatkan perbandingan kayu gergajian dengan waktu yang dibutuhkan selama proses penggergajian kayu tersebut berlangsung dengan memperhatikan waktu jam kerja yang diberlakukan di CV. Sinar Jaya. Jam kerja di CV. Sinar Jaya dimulai dari pukul 08.00-16.00 (delapan jam kerja). Berdasarkan hal tersebut, produktivitas di CV Sinar Jaya disajikan pada Tabel 2 dan 3. antara 2,8-3 m pada berbagai ukuran sortimen (Tabel 1). Rendemen pengolahan kayu sangat tergantung dari ukuran diameter kayu, keterampilan pengergaji kayu, dan bentuk silindris kayu. Bentuk silindris mencakup juga kondisi cacat yang dapat mereduksi kayu (mata kayu gubal busuk dan gerowong).

\begin{tabular}{ccccc}
\multicolumn{6}{l}{ Tabel 2. Produktivitas } \\
\hline No & $\begin{array}{c}\text { Volume } \\
\left(\mathrm{m}^{3}\right)\end{array}$ & Sortimen & $\begin{array}{c}\text { Jam } \\
\text { Kerja }\end{array}$ & $\begin{array}{c}\text { Hasil } \\
\left(\mathrm{m}^{3} / \mathrm{jam}\right)\end{array}$ \\
\hline 1 & 11.45 & $\mathrm{~KB}$ & 8 & 1.43 \\
1 & 14.62 & $\mathrm{~KB}$ & 8 & 1.83 \\
1 & 10.15 & $\mathrm{~KB}$ & 8 & 1.27 \\
$\begin{array}{c}\text { Rata- } \\
\text { Rata }\end{array}$ & 12.07 & $\mathrm{~KB}$ & & 1.51 \\
1 & 6.61 & $\mathrm{KG}$ & 8 & 0.83 \\
1 & 7.72 & $\mathrm{KG}$ & 8 & 0.97 \\
1 & 5.66 & $\mathrm{KG}$ & 8 & 0.71 \\
$\begin{array}{c}\text { Rata- } \\
\text { Rata }\end{array}$ & 6.67 & $\mathrm{KG}$ & & 0.83 \\
\hline
\end{tabular}

Sumber Data Primer 2021

Tabel 3. Produktivitas dalam interval waktu

\begin{tabular}{clccc}
\hline No & Waktu & $\begin{array}{c}\text { Jumlah } \\
\text { Hari }\end{array}$ & $\begin{array}{c}\text { Kayu } \\
\text { Bulat } \\
\left(\mathrm{m}^{3}\right)\end{array}$ & $\begin{array}{c}\text { Kayu } \\
\text { Gergajian } \\
\left(\mathrm{m}^{3}\right)\end{array}$ \\
\hline 1 & 1 Hari & 1 & 12.07 & 6.67 \\
2 & 1 Minggu & 6 & 72.44 & 40.00 \\
3 & 1 Bulan & 24 & 289.76 & 159.98 \\
4 & 1 Tahun & 288 & $3,477.12$ & $1,919.77$ \\
\hline \multicolumn{2}{l}{ Sumber }
\end{tabular}

Sumber Data Primer 2021 
Proses produksi di CV. Sinar Jaya dengan menggunakan mesin band saw. Menurut Silviana dan Ismail (2017), penggunaan mesin bandsaw berpengaruh terhadap produktifitas. Dengan jumlah pekerja sebanyak sebanyak 3 orang dengan jumlah mesin Band Saw utama sebanyak 1 (satu) unit dengan produktivitas kayu bulat rata-rata $1,5 \mathrm{~m}^{3} / \mathrm{jam}$ dan 12,07 $\mathrm{m}^{3} /$ hari sedangkan kayu gergajian $0,83 \mathrm{~m}^{3} /$ jam dan $6,67 \mathrm{~m}^{3} / \mathrm{jam}$. Menurut Standar Operasional Prosedur Pengolahan Kayu yang Efisien tahun 2009,kecepatan mesin Band Saw disarankan pada kisaran 1.800 s.d 2.000 RPM dengan batas bahaya getaran 11,2 m/detik. Kapasitas maksimum mesin Band Saw 2.000 jam kerja dalam satu tahun maka mesin yang berkerja di CV Sinar Jaya (24 hari $\times 8$ jam x 12 Bulan $)=$ 2.304 jam /tahun terdapat kelebihan 304 jam dalam kurun waktu 1 tahun dengan catatan bahwa produk afkir tidak dihitung.

\section{Perhitungan Limbah}

Limbah penggergajian kayu berupa potongan kayu dan serbuk gergajian. Rata-rata limbah yang dihasilkan dari setiap batang kayu dan presentase limbah disajikan pada Tabel 4.

Tabel 4. Perhitungan Limbah

\begin{tabular}{cccc}
\hline No & $\begin{array}{c}\text { Jumlah } \\
\text { Kayu Bulat } \\
\text { (Batang) }\end{array}$ & $\begin{array}{c}\text { Volume } \\
\text { Limbah } \\
\text { Rata-Rata } \\
\left(\mathrm{m}^{3}\right)\end{array}$ & $\begin{array}{c}\text { Prosentase } \\
\text { Limbah } \\
\text { Rata-Rata } \\
(\%)\end{array}$ \\
\hline 1 & 120 & 0.04 & 42.77 \\
2 & 180 & 0.04 & 48.87 \\
3 & 183 & 0.02 & 53.89 \\
Rata & 161 & 0.03 & 48.51 \\
Rata & 161 & & \\
\hline
\end{tabular}

Sumber Data Primer 2021
Nilai limbah didapat dari perhitungan volume kayu bulat dikurangi dengan volume kayu gergajian pada setiap satuan kayu yang telah diolah. Setelah didapat nilai rendemen dari pengolahan tersebut maka prosentase limbah didapat dari pengurangan bahan baku dikurangi dengan nilai rendemen. Prosentase rata-rata limbah di CV. Sinar Jaya sebesar $48,51 \%$. Nilai tersebut dipengaruhi oleh kondisi diameter kayu, keterampilan penggergagaji, dan sortimen yang dihasilkan. Limbah berupa potongan kayu dan serbuk gergajian dan kulit dimanfaatkan sebagai bahan baku kayu bakar industri pembuatan Tahu, sedangkan serbuk gergajian dimanfaatkan sebagai bahan baku pembakaran industri pembuatan batu bata tradisional yang masih dapat dimanfaatkan oleh masyarakat lainya dengan harga untuk kayu bakar Rp.70.000/pick up sedangkan serbuk gergajian Rp. 2.000/karung rata-rata limbah yang dihasilkan dari setiap batang kayu.

\section{B. Nilai Usaha}

\section{Biaya Penyusutan Alat}

Biaya Penyusutan merupakan alokasi yang dapat disusutkan untuk masa pemanfaatan atau penggunaannya dalam suatu aktivitas produksi. Metode perhitungan penyusutan suatu aset merupakan pertimbangan suatu aset tersebut memberikan dampak atau nilai ekonomis yang relatif sama pada setiap periode waktu masa penggunaan atau setiap tahunnya (Tabel 5).

Tabel 5. Biaya Penyusutan CV. Sinar Jaya

\begin{tabular}{|c|c|c|c|c|c|}
\hline No & Unit & $\begin{array}{c}\text { Harga } \\
\text { (Rupiah) }\end{array}$ & $\begin{array}{l}\text { Residu } \\
\text { (Rupiah) }\end{array}$ & $\begin{array}{l}\text { Masa } \\
\text { Pakai }\end{array}$ & $\begin{array}{c}\text { Nilai } \\
\text { (Rupiah) }\end{array}$ \\
\hline 1 & $\begin{array}{l}\text { Mesin Ban } \\
\text { Saw }\end{array}$ & $25,000,000$ & $2,500,000$ & 10 Tahun & $2,250,000$ \\
\hline 2 & $\begin{array}{l}\text { Gedung Semi } \\
\text { Permananen }\end{array}$ & $30,000,000$ & $3,000,000$ & 10 Tahun & $2,700,000$ \\
\hline 3 & Mesin Diesel & $9,000,000$ & 900,000 & 5 Tahun & $1,620,000$ \\
\hline
\end{tabular}

Sumber Data Primer 2021 


\section{Biaya Produksi}

Biaya Produksi merupakan nilai angka rupiah yang harus dikeluarkan untuk mendapatkan hasil dari suatu proses kegiatan produksi menghasilkan suatu nilai barang atau jasa. Biaya produksi meliputi biaya tetap dan biaya tidak tetap dalam interval waktu tertentu (Tabel 6).

Tabel 6. Biaya Produksi

\begin{tabular}{clcr}
\hline No & Waktu & $\begin{array}{c}\text { Jumlah } \\
\text { Hari }\end{array}$ & \multicolumn{1}{c}{$\begin{array}{c}\text { Biaya } \\
\text { Produksi }\end{array}$} \\
\hline 1 & 1 Hari & 1 & $4,040,000$ \\
2 & 1 Minggu & 6 & $24,560,000$ \\
3 & 1 Bulan & 24 & $102,000,000$ \\
4 & 1 Tahun & 288 & $1,181,600,000$ \\
\hline \multicolumn{4}{l}{ Sumber Data Primer 2021}
\end{tabular}

Tabel 7. Nilai Ekonomi Limbah

\begin{tabular}{lcccc}
\hline $\begin{array}{c}\text { Jenis } \\
\text { limbah }\end{array}$ & Jumlah & $\begin{array}{c}\text { Harga } \\
(\mathrm{Rp})\end{array}$ & Satuan & $\begin{array}{c}\text { Total } \\
(\mathrm{Rp})\end{array}$ \\
\hline $\begin{array}{l}\text { Afkir } \\
\text { Limbah } \\
\text { kayu }\end{array}$ & 100 & 2.000 & $\begin{array}{c}\text { Hari } \\
\text { Pickup } \\
\text { /hari }\end{array}$ & 1400,0000 \\
$\begin{array}{l}\text { Serbuk } \\
\text { gergaji }\end{array}$ & 100 & 1,500 & $\begin{array}{c}\text { Karung/ } \\
\text { Minggu }\end{array}$ & 150,000 \\
Total & & & & 490,000 \\
\hline
\end{tabular}

Sumber : Data Primer (2021)

\section{Nilai Pendapatan}

Nilai Pendapatan utama atau perolehan didapat dari banyaknya jumlah kayu gergajian yang dihasilkan yang kemudian dikalikan dengan harga pada masing masing sortimen kayu gergajian tersebut dalam kurun waktu tertentu, besarnya pendapatan dari sebuah aktivitas produksi secara keseluruhan dari aktivitas produksi kayu bulat yang di konversi ke dalam kayu gergajian dengan harga per masing- masing unit. Selain dari hasil kayu gergajian, pendapatan juga diperoleh dari pendapatan tambahan dari produk kayu afkir (reject) dan limbah kayu serta sebuk kayu.

Berdasarkan data sekunder diperoleh pendapatan total CV. Sinar Jaya dalam 1 minggu (Tabel 9).

Tabel 9 Nilai Pendapatan Selama Satu Minggu

\begin{tabular}{ccccc}
\hline No & Tanggal & $\begin{array}{c}\text { Jumlah } \\
(\mathrm{kg})\end{array}$ & $\begin{array}{c}\text { Volume } \\
\left(\mathrm{m}^{3}\right)\end{array}$ & Nilai Total \\
\hline 1 & 15 Maret 2021 & 695 & 5.703 & $3,789,000$ \\
2 & 16 Maret 2021 & 512 & 10.0341 & $7,235,000$ \\
3 & 17 Maret 2021 & 738 & 6.5394 & $5,296,000$ \\
4 & 18 Maret 2021 & 800 & 7.2696 & $7,944,000$ \\
5 & 19 Maret 2021 & 579 & 5.5188 & $5,333,000$ \\
6 & 20 Maret 2021 & 925 & 8.751 & $9,981,000$ \\
& Total & 4249 & 43.8159 & $39,578,000$ \\
\hline
\end{tabular}

Sumber : Data Primer (2021)

\begin{tabular}{cccccc}
\multicolumn{6}{l}{ Tabel 8. Nilai Pendapatan } \\
\hline \multirow{2}{*}{ No } & $\begin{array}{c}\text { Jumlah } \\
\text { Keping }\end{array}$ & $\begin{array}{c}\text { Nilai } \\
\text { Pendapatan }\end{array}$ & Reject & $\begin{array}{c}\text { Limbah } \\
\text { Kayu }\end{array}$ & Jumlah \\
\hline 1 & 670 & $4,767,000$ & 200,000 & 140,000 & $5,107,000$ \\
2 & 642 & $5,926,000$ & 200,000 & 140,000 & $6,266,000$ \\
3 & 564 & $3,937,000$ & 200,000 & 140,000 & $4,277,000$ \\
& & & & Rata- & \\
& 625 & $4,876,666.67$ & & Rata & $5,216,666.1$ \\
\hline
\end{tabular}

Sumber Data Primer 2021

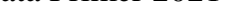




\section{Nilai Keuntungan Bersih}

Nilai keuntungan bersih dapat diketahui dengan menghitung selisih antara penerimaan total (total revenue) dan biaya total (total cost). Nilai keuntungan bersih disajikan pada Tabel 10.

Tabel 10. Nilai Keuntungan Bersih

\begin{tabular}{clccc}
\hline No & Waktu & $\begin{array}{c}\text { Total } \\
\text { Revenue }\end{array}$ & $\begin{array}{c}\text { Total } \\
\text { Cost }\end{array}$ & $\begin{array}{c}\text { Keuntungan } \\
\text { Bersih }\end{array}$ \\
\hline 1 & 1 Hari & $5,216,666.67$ & $4,040,000$ & $1,176,666.67$ \\
2 & 1 Minggu & $31,450,000$ & $24,560,000$ & $6,890,000$ \\
3 & 1 Bulan & $125,800,000$ & $102,000,000$ & $23,800,000$ \\
4 & 1 Tahun & $1,509,600,000$ & $1,181,600,000$ & $328,000,000$ \\
\hline
\end{tabular}

Sumber : Data Primer (2021)

\section{Nilai Biaya Pemasaran}

Biaya pemasaran merupakan biaya yang dikeluarkan dalam rangka pemasaran hasil produk tertentu. CV Sinar Jaya tidak melakukan promosi sehingga biaya pemasaran cenderung tidak ada. Produk kayu gergajian lebih banyak di pasarkan di sekitar Kecamatan Cigudeg dan sekitarnya. Permintaan produk dilakukan oleh konsumen dengan cara langsung datang ke CV. Sinar Jaya. Biaya hanya akan dikeluarkan pada kondisi tertentu (tentatif) yang membutuhkan negosiasi dalam kesepakatan kontrak kerja baru.

\section{Nilai Benefit Cost Ratio}

Nilai BCR digunakan sebagai alat untuk menganalisis kelayakan usaha. Nilai $B C R$ dapat dilihat pada Tabel 11.

Tabel 11. Nilai Benefit Cost Ratio

\begin{tabular}{clccc}
\hline No & Waktu & $\begin{array}{c}\text { Penerimaan } \\
\text { Total }\end{array}$ & Biaya Total & $\begin{array}{c}\text { Nilai } \\
B C R\end{array}$ \\
\hline 1 & 1 Hari & $5,216,666.67$ & $4,040,000$ & 1.29 \\
2 & 1 Minggu & $31,450,000$ & $24,560,000$ & 1.28 \\
3 & 1 bulan & $125,800,000$ & $102,000,000$ & 1.23 \\
4 & 1 Tahun & $1,509,600,000$ & $1,181,600,000$ & 1.27 \\
\hline
\end{tabular}

Sumber : Data Primer (2021)

Tabel 11 menunujukkan bahwa nilai BCR dalam 1 tahun sebesar 1,27, dengan demikian maka usaha pengolahan kayu CV. Sinar Jaya dapat katagorikan menguntungkan atau layak untuk dilanjutkan.

\section{Nilai Prestasi Kerja}

Pembayaran yang dilakukan di CV. Sinar Jaya dilakukan berdasarkan prestasi kerja yang dihasilkan oleh pekerja. Pembayaran dilakukan dengan menggunakan metode borongan kepada 3 orang (penggergaji, pemilih kayu, dan helper) dengan nilai sebesar Rp. 450.000/hari untuk 8 jam. Perhitungan nilai prestasi kerja di CV Sinar Jaya disajikan pada Tabel 12.

Tabel 12. Nilai Prestasi Kerja

\begin{tabular}{ccccc}
\hline No & $\begin{array}{c}\text { Upah } \\
(\mathrm{Rp})\end{array}$ & $\begin{array}{c}\text { Volume } \\
\left(\mathrm{m}^{3}\right)\end{array}$ & Sortimen & $\begin{array}{c}\text { Pendapatan } \\
(\mathrm{Rp})\end{array}$ \\
\hline 1 & 150,000 & 11.45 & $\mathrm{~KB}$ & $13,100.44$ \\
2 & 150,000 & 14.62 & $\mathrm{~KB}$ & $10,259.92$ \\
3 & 150,000 & 10.15 & $\mathrm{~KB}$ & $14,778.33$ \\
& Rata-Rata & 12.07 & $\mathrm{~KB}$ & $12,712.89$ \\
1 & $150,000.00$ & 6.614 & $\mathrm{KG}$ & $22,678.48$ \\
2 & $150,000.00$ & 7.723 & $\mathrm{KG}$ & $19,421.65$ \\
3 & $150,000.00$ & 5.660 & $\mathrm{KG}$ & $26,501.30$ \\
& Rata-Rata & 6.67 & $\mathrm{KG}$ & $22,867.14$ \\
\hline
\end{tabular}

Sumber : Data Primer (2021)

Untuk menghindari kerugian pemilik CV. Sinar Jaya menargetkan perolehan kayu gergajian dalam satu hari minimal 6 sampai 8 $\mathrm{m}^{3} /$ hari hal ini dikarenakan jumlah biaya produksi dalam satu hari sendiri cukup besar. Perolehan prestasi kerja tersebut untuk kayu bulat rata-rata adalah sebesar $12,07 \mathrm{~m}^{3}$ dengan nilai nominal pendapatan $\mathrm{Rp} 12.712,89$. 
Sedangkan rata-rata prestasi kerja untuk kayu gergajian $6,67 \mathrm{~m}^{3}$ nilai nominal pendapatan Rp. 22.867.14. Nilai prestasi kerja tersebut dipengaruhi oleh ketersedian bahan baku kayu bulat, keterampilan atau keahlian penggergaji, dan sortimen yang dihasilkan.

\section{KESIMPULAN}

Berdasarkan hasil penelitian yang telah dilakukan maka dapat diambil kesimpulan :

1. Rendemen pengolahan kayu gergajian di CV. Sinar Jaya rata-rata sebesar 54,94\%.

2. Produktivitas pengelolaan kayu CV. Sinar Jaya sebesar $0,83 \mathrm{~m}^{3} / \mathrm{jam}$ dengan nilai benefit cost ratio 1,28 (layak diusahakan).

\section{UCAPAN TERIMAKASIH}

Terimakasih kepada CV. Sinar Jaya dan semua pihak yang telah membantu terlaksananya penelitian ini dengan baik.

\section{DAFTAR PUSTAKA}

Asyisifa. 2009. Analisis Biaya dan Pendapatan Industri Mebel Jati di Banjarbaru Kalimantan Selatan. Program Studi Manajemen Hutan, Fakultas Kehutanan, Universitas Lambung Mangkurat. Pontianak.

Bakti, G. F., Supriono, B., \& Meiganati, K. B. (2018). Pendugaan Potensi Tegakan dan Kontribusi Hutan Rakyat terhadap Pendapatan Masyarakat di Kecamatan Cigudeg Kabupaten Bogor (Estimation of Stands Potential and Contribution of People's Forest on Community Income in Cigudeg District, Bogor Regency). Jurnal Nusa Sylva, 18(2), 90-97.

Hardjanto. 2017. Pengelolaan Hutan Rakyat. Bogor : IPB Press.

Laksono, A. D., Susdiyanti, T., \& M, K. B. (2016). produktivitas dan Rendemen Industri Penggergajian Kayu di Kecamatan Cigudeg Kabupaten Bogor (Productivity and Yield Industrial Sawmills in Cigudeg District of Bogor. Jurnal Nusa Sylva, 16(2), 50-58.

Mardiatmoko, Gun, J.H. Pietersz dan A. Boreel. 2014. Ilmu Ukur Kayu dan Inventarisasi Hutan. Ambon: Badan Penerbit Fakultas Pertanian Universitas
Patimura.

Mazni, M., Sadjati, E., \& Insusanty, E. (2017). Analisis Biaya Industri Kecil Pengolahan Kayu Dan Perabot Di Pangkalan Kerinci Kabupaten Pelalawan (Studi Kasus UD. Auzar Bersaudara dan UD. Dirgantara). Wahana Forestra: Jurnal Kehutanan, 12(2), 1-19. https://doi.org/10.31849/forestra.v12i2.205

Peraturan Direktur Jenderal Bina Produksi Kehutanan Nomor P.14/VI-BIKPHH/2009

Peraturan Direktur Jenderal Bina Usaha Kehutanan No. P.12/VI- BPPHH/2014 tentang Rendemen Kayu Olahan Industri Primer Hasil Hutan Kayu

Randam, Rosidah R, 2011. Studi Produktivitas dan Rendemen Industri Penggergajian Kayu Akasia Daun Lebar (Acacia mangium Willd) di Kecamatan Landasan Ulin Kota Banjarbaru Kalimantan Selatan. Jurnal Hutan Tropis Volume 12 No.31

Rosidah R Radam. (2011). Studi Produktivitas dan Rendemen Industri Penggergajian Kayu Akasia Daun Lebar (Acacia mangium Willd) di Kecasmatan Landasan Ulin Kota Banjarbaru Kalimantan Selatan. 12(31), 99-107.

Sari, D. I. (2018). Analisis Depresiasi Aktiva Tetap Metode Garis Lurus dan Jumlah Angka Tahun PT Adira Dinamika. Jurnal Moneter, V(1), 86-92.

Silviana, \& Ismail, N. R. (2017). Peningkatan Produktivitas Proses Produksi Pengrajin Kusen dan Pintu Berbasis Mesin Band Saw Senaspro UMM, 349-355.

Sopianoor, Zuhdi Yahya, Maya Preva Biantary. 2011. Studi Rendemen Bahan Baku Log Pada IU-IPHHK Rusmandiansnyah Di Kecamatan Damai Kabupaten Kutai Barat. AGRIFOR Volume XV Nomor 2, Oktober 2016, 12(31), 99-107.

Sugiyono.2015. Metode Penelitian Pendidikan Pendekatan Kualitatif Kualitatif dan R\&D. Bandung: Alfabeta.

Taher, MHD Tarmizi.2017. "Potensi Peningkatan Nilai Ekonomi Pemanfaatan Kayu Hutan Rakyat di Desa Cisampih, Kecamatan Banjarsari, Kabupaten Lebak Banten (Kasus Pada Kayu Dimater 10-15 cm)" Fakultas Kehutanan. IPB.Bogor.

Uar, N. I. (2016). Produktivitas dan Rendemen Kayu Gergajian Pada Perusahaan IUIPHHK PT. Katingan Timber Celebes. Agrikan: Jurnal Agribisnis Perikanan, 9(1), 16. https://doi.org/10.29239/j.agrikan.9.1.16-22 